\title{
Oração do Paranympho á Turma de Bachareis de 1937
}

\author{
Pronunciada na solennidade da col- \\ lação de grau realizada, em 18 de ja- \\ neiro de 1938, no Theatro Municipal \\ de São Paulo.
}

\section{Jorge Americano}

Meus alumnos, quasi filhos até hontem, collegas desde hoje, amigos hontem, hoje e sempre:

Vivemos juntos, de presença e de coração.

Entretanto, não me é facil falar-vos.

Conforme temos vivido mais, ou menos, ha intensidade e vigor diversos na expressão. Quem emitte uma palavra, nunca sabe, certo, o que ella desperta nos que o ouvem.

Mais que nunca, neste tempo, não é facil falar aos jovens. Ha um antagonismo entre as gerações, fructo da rapida transmutação das idéas universaes. Já não varia só o valor intensivo da expressão, conforme quem a profere, mas tambem o qualitativo, conforme as coisas a que se applica.

Si então, os moços que nos ouvem são juristas, difficilimo é falar-lhes: Cada um é uma accusação viva ás gerações que, organizando juridicamente o mundo, não lhe imprimiram uma feição coherente, ordenada e pacifica.

Querendo ouvir de mim a oração de despedida, a honra que me déstes envolve a interpellação anciosa sobre as directrizes que deveis seguir. 
Recebestes a investidura que habilita a proteger ou dirigir fortuna, honra e vida, tanto de um homem, como de um grupo, como de um paiz.

Olhae para a confusão do mundo: povos que se atiram uns contra os outros; nações que a si mesmas se destroem; homens que não se comprehendem e se combatem; orçamentos em desequilibrio, moedas desvalorizadas, fronteiras fechadas ao commercio; custo de vida elevado; leis que visam certo escopo e produzem diverso e inesperado effeito.

Si quizerdes comprehender o que se passa, lêde André Siegfried, e vereis que, procurando conjugar o presente ao passado do fim do seculo XIX, a interpretação do presente é menos obscura.

A Europa detinha, áquelle tempo, a direcção economica do mundo. Fornecia todos os mercados da terra com artigos cuja materia prima importava e reexportava manufacturada. Tinha o monopolio dos encaixes em ouro e era, por força, o centro da politica economica mundial.

Mas já havia, ao fim do seculo, indices precursores da mudança, signaes que ninguem então percebia, e que logo depois se acentuaram, começando a transformar aquelle estado de coisas. E' que os machinismos europeus exportados haviam de, fatalmente, crear centros de producção concurrentes, nas outras partes da terra.

Isto, que já se delineava antes, accentuou-se com a guerra de 1914, quando das fabricas e da lavoura foram tirados e devorados pela lucta milhões de homens.

Reduzida a capacidade productora européa e aggravada a sua capacidade consumidora dos artigos essenciaes á guerra, a Europa solicitou aos outros continentes uma intensidade de producção, cujo fornecimento lhes aperfeiçou as possibilidades e lhes preparou a emancipação economica. Nações como os Estados Unidos e o Japão, já apparelhados para a actividade industrial, accrescentaram á suas balan- 
ças commerciaes saldos vultosos, e fizeram enormes encaixes bancarios, passando a concorrer com a Europa, na direcção economica do mundo. Outros paizes, como o nosso, apezar do grande surto, não puderam manter a posição, suppletiva e não de primazia. Mas o facto é que, finda a guerra, mesmo estes paizes contribuiram para o desequilibrio da velha situação economica, pois deixaram de ser tributarios da Europa e passaram a se-lo, pelo menos em parte, dos Estados Unidos e até do Japão.

Não obstante taes factos, absolutamente caracteristicos de uma nova ordem economica, a mentalidade européa se manteve no seculo XIX, cujo feitio entendeu necessario sustentar a todo o transe.

o que era fatal, foi o deslocamento do eixo economico, preparado pelo seculo XIX, e apressado pela guerra. Mas o que se entendeu, não foi a realidade dos factos novos, senão a supposição de que as leis economicas estavam erradas. Então, cada paiz europeu se fez um compartimento estanque á invasão dos productos extrangeiros; e cada paiz não europeu, de industria incipiente, entendeu de protege-la e anima-la, prohibindo a entrada do similar extrangeiro.

Em defesa de tal systema seguiu-se, em todas as nações, o assoberbamento das despezas militares. De tudo, resultou o encarecimento assustador do custo da vida. Correlatamente, grande parte das relações juridicas passou a soffrer revisão, no intuito de justificar e defender a ordem de coisas, imposta pela nova economia. Intentou-se crear um direito novo.

Mas, nota Ripert, que se quer crear um direito novo sem saber ao certo o que elle deva ser. Ninguem jamais duvidou de que haja uma evolução do direito. Porém, o mundo moderno está convencido do caracter necessario de tal evolução, e os dirigentes entendem não dever impedi-la ou retarda-la: apressam-na.

Tão justa observação faz perguntar: qual o sentido dessa evolução? 
Os mais argutos observadores não no-lo dizem. Uns povos parecem atirar-se numa direcção e outros na direcção opposta. Essas orientações divergentes se approximarão mais adiante? Ou divergirão indefinidamente? $\mathrm{E}$ aonde irão ter?

Um ponto nunca determina uma direcção. O momento presente é um ponto no tempo. Delle, tirar-se-iam linhas em qualquer sentido. Dois pontos, pelo menos, são necessarios para traçar uma linha. Si se quer estabelecer que, no direito, devemos abandonar a lição do passado, o passado já não servirá como indice de referencia, pelo qual se traçará a linha que vae orientar o futuro.

Ora, raciocinemos. $O$ presente é differente. Mas ser differente não é ser, necessariamente, contrario. Se o passado tinha um sentido, e o presente parece ter outro, tambem é certo que, na sociedade como na natureza, nada se muda brusca e fundamentalmente. Aquillo a que chamamos grande transformação é, o mais das vezes, ligeira inflexão sobre a directriz anterior.

Aquillo em que o passado é realmente differente do presente, não é o phenomeno juridico, nem o facto sociologico, pelo menos na intensidade differencial que se lha quer emprestar.

O que mais differe é a velocidade caracteristica dos acontecimentos modernos. Os descobrimentos scientificos approximam os homens. Accelerada a permuta do pensamento, a acção se multiplica. Approximado o pensamento e multiplicada a acção, mais evidentes se mostram os antagonismos entre os factos successivos.

Antigamente, a linha espiral ascensional do progresso humano talvez não fosse diversa da actual. Mas a suave marcha dos acontecimentos, percorrendo essa curva que, em planos differentes, indefinidamente passa sobre o traçado anterior, não permittia mostrar-se tão flagrante a constante mudança das direç̧ões. A's vezes, chegava a parecer que o caminho era uma recta indefinida. 
Hoje, a acceleração da marcha evidenciando mais uma vez que o progresso não segue a direcção rectilinea, porém a espiral ascensional, crea na civilização um estado vertiginoso, decorrente da velocidade excessiva.

A' antiga suavidade das curvas percorridas em marcha reduzida, substituem-se sensações violentas.

A linha do progresso não mudou. Era e continua a ser uma espiral ascensional. Accentuada, entretanto, a acceleração, perturbaram-se os conceitos sobre o progresso.

A' pergunta, que leio no vosso olhar, sobre o que deva ser o futuro, e o que nelle sereis, não poderia responder-vos. Cada geração faz muito, ao transmittir o facho á successora, quando lhe traça o estado actual dos problemas a resolver. Exorbita porém, si além de ligeiras advertencias, querlhe impôr as soluções. Desde que não as possa realizar, não tem o direito de impôr aos novos como deverão fazer. Nada vos direi neste sentido, portanto.

Evitareis, todavia, a excessiva acceleração evolutiva. Consultareis a tradição e a experiencia, em que acreditaes tão pouco, tão nóvos sois, tão confiantes, tão certos de vencer.

Consulta-las-eis, embora contando pouco com essas forças que defendem as nações velhas do mundo. Procurareis atenuar os impulsos incoherentes da crise de crescimento de um povo joven.

Ouvireis o sabio conselho de Ripert para que não imagineis toda reforma um progresso, nem tambem negueis cegamente a necessidade de fazer evolver o direito e reformar as instituições.

Quando, pela primeira vez, defrontei-me convosco, emquanto tentaveis formar juizo do professor, tambem eu procurava julgar-vos, não só na capacidade acquisitiva dos conhecimentos, mas ainda como personalidades humanas que vos projectareis adiante de nós no tempo, e que levareis ao futuro alguma coisa das gerações que vos viram nascer, que vos educaram, instruiram-vos, amaram-vos e em vós confiaram. 
$\mathrm{Na}$ feição, no olhar, na confiança ou no scepticismo com que nos ouvieis, procuravamos o signal interpretativo da orientação na marcha para o futuro, em cujos processos nós professores collaboramos atravez de vós, embóra as soluções nos sejam imprevisiveis, embora certos, tambem, de que dellas não gozaremos os fructos.

Não sei si viestes ao estudo do direito, por chamamento intimo e irresistivel, unico a que realmente se póde denominar vocação, e que só acena a raros entes; ou se vos determinastes por uma escolha deliberada; ou se vos deixastes trazer pelos imponderaveis que nos conduzem o mais das vezes.

Mas viestes. E, neste passo, proferistes um juramento. Assumistes a responsabilidade, não só do desempenho honesto da profissão, mas do encaminhamento das gerações que receberão a vossa influencia, e que exigem a solução organica, exacta e humana dos problemas modernos.

Ao collar gráo, agora mesmo fostes exhortados a vos afastar do mal, a temer o erro, a defender a lei, a trabalhar pelo bem publico.

Jurastes honradez, devotamento á justiça, á moral, á causa da humanidade.

Sabeis o que vale tal promessa?

Cultura da intelligencia. Polidez e medida da palavra. Diligencia attenta e acção infatigavel. Senso de justiça e nobreza de ideaes. Lisura na vida. Immenso respeito á dignidade humana. Energia no combate, serenidade na derrota, grandeza d'alma na victoria.

A tanto vos obrigastes ao vos decidirdes pela profissão de jurista. Decidistes-vos por ella sem temor, e fizestes bem.

Carrel diz que cada decisão tomada na vida, mata dentro em nós um ser virtual, aquelle que poderiamos ter sido se houvessemos tomado o outro ramo da encruzilhada, que deixámos de seguir. No começo da vida, o homem tem dentro em si numerosos seres virtuaes que morrem um a um, a cada encruzilhada transposta, a cada decisão tomada. 
O velho é rodeado pelo cortejo daquelles que poderia ter sido, de todas as suas possibilidades abandonadas. $O$ tempo nos transforma de fluido em solido. Por effeito delle, somos thezouro que se desperdiça, historia que se escreve, ou personalidade que se crea. A ascensão ou a queda dependem de factores physicos, chimicos e physiologicos, mas tambem da influencia psychica do meio e da vontade propria. Somos construidos quer pelo meio, quer por nós mesmos.

Quando por vós mesmos escolhestes a profissão de juristas, mataste dentro em vós muitos dos outros seres virtuaes. Sereis, pelo direito, maiores que tudo quanto deixastes para serdes juristas.

Juristas novos num paiz tão novo, a surgir em meio de um mundo tão velho, que emquanto a Europa celebra, neste anno que vae entrando, o bi-millenario de Augusto, nós temos por tradição cultural valiosissima e gloria muito alta os nossos 110 annos da Faculdade de Direito de São Paulo; tradição que respeitareis, gloria que accrescentareis.

mas, ao falar em tradição concentremo-nos, na homenagem aos mortos que a vossa turma conheceu na escola: Gama Cerqueira, Villaboim, Raphael Sampaio, Julio Maia, que fizeram tanto pela tradição, pela casa, e por via della, pela terra. Recordemos a juventude de Ennio Bicudo, Victorino Vianna, Fernando Amaral, Said Calil, tombados em plena gloria da mocidade.

tradição e gloria que accrescentareis, tão profundamente ligados á escola, tão genios della propria, sentindo-lhe tanto as vibrações, as palpitações, a consciencia profunda, sem embaraço da inquietação que agora vos faz interrogar, sem resposta, como haveis de desempenhar nobremente a funcção que vos couber - funcção orientadora, quer vos dediqueis á advocacia, quer vos dirijaes á magistratura, á politica, ás letras juridicas, pois o homem culto orienta ainda que o não queira, dirige embora se afaste do poder, governa pela diffusão do pensamento. 
Já attentastes para a angustiada perplexidade dos primeiros povoadores da capitania de São Vicente, quando pisando o littoral alagadiço, levantaram a vista para a serra do Mar, para o sertão, para o futuro? Os três reinos da natureza lhes pareciam inimigos, e os attrahiam; a floresta envolvente e impenetravel; o minerio seductor, cuja interminavel procura iria destruir esperanças, arruinar posses e devorar vidas; o animal e o homem indigena, espiando, atacando, disputando o passo ao invasor; "a cada volta a morte afiando o olhar faminto"

Mas elles venceram. Construiram a patria.

Sereis da mesma tempera. Os problemas se vos apresentam com escolhos tão grandes como os que foram vencidos pelos nossos maiores.

Elles construiram uma nova patria. Tendes que situala dentro de um mundo velho.

E vencereis.

Vencer não é só chegar ao mais alto, onde vos auguro que chegareis. Vence-se, quando se vive com honra. Vence-se, quando se renova a propria cultura.

Ide, renovando-vos: olhando, apprendendo e applicando. Na renovação mental tereis fonte inexgotavel de alegrias.

Assuma cada um o seu papel. Cada qual trabalhará alentado pela certeza de que as quasi duas centenas de obreiros seus irmãos, que agora tomam os caminhos diversos da vida, trabalham pela causa commum.

Conservae a emoção desta hora. Da vida, que imperiosamente vos chama, é uma das maiores horas.

Ide, levando a lembrança imperecivel do vosso juramento. 